\title{
IMPACTOS DA REESTRUTURAÇÃO PRODUTIVA E ESPACIAL NA ATIVIDADE AGRÍCOLA DO BAIXO JAGUARIBE-CE
}

\author{
IMPACTS OF THE PRODUCTIVE AND SPATIAL RESTRUCTURING IN \\ THE LABOR MARKET OF BAIXO JAGUARIBE-CE
}

\section{IMPACTO DE LA REESTRUCTURACIÓN PRODUCTIVA Y ESPACIAL EN LA ACTIVIDADE AGRÍCOLA DEL BAJO JAGUARIBE-CE}

\author{
Alexsandra M. V. Muniz \\ Doutoranda e Professora do Departamento de Geografia da Univ. Federal do Ceará \\ Campus do Pici - Bloco 911 - Cep: 60455-760, Fortaleza-CE \\ Email: geoalexsandra@ufc.br/alexsandramuniz@yahoo.com.br \\ Denise Elias \\ Doutora em Geografia Humana, Professora do Programa de Pós Graduação em Geografia da UECE \\ Email: deniselias@uol.com.br
}

\begin{abstract}
Resumo
O presente artigo constitui a análise de uma das dimensões da atual fase de expansão mundial do capitalismo, qual seja: a reestruturação produtiva e consequentemente espacial em curso. A dinâmica do desenvolvimento capitalista está provocando transformações- na economia, nas relações sociais, na política, na cultura e, no mundo do trabalho também está operando mudanças quantitativas e qualitativas. Procuramos proporcionar uma clara compreensão do instrumento lógico-conceitual em que se apóia a presente análise. Por tratar-se de uma análise multidisciplinar, a abordagem da temática exigiu o recurso a um corpo teórico que fornecesse a compreensão da realidade, tendo como referência autores não somente da geografia, como também, mantivemos diálogo com economistas e sociólogos. Buscamos assim evidenciar as especificidades do processo em curso que mais de perto afetam o processo produtivo, as relações e organização do trabalho, notadamente no espaço rural, realizando uma análise geral acerca do Paradigma de Acumulação Flexível, de modo a situar as particularidades no todo dentro do qual é definida sua presença, já que um estudo de caso desarticulado do todo é capaz de turvar a compreensão do processo real.
\end{abstract}

Palavras-chave: Reestruturação da produção e do espaço, Relações de trabalho, Mundialização do Capital

\section{Abstract}

This article present is an analysis of the dimensions of the current phase of global expansion of capitalism, which is: the production restructuring and consequently spatial at progress. The dynamics of capitalist development is generating to changes- in the economy, in the social relations, in the politics, in the culture, and in the world of work 
also is operating quantitative and qualitative changes. We seek to provide a clear understanding of the conceptual-logical tool that supports this analysis. Because it is a multidisciplinary analysis, the approach of the thematic demanded the resources to a theoretical framework that provides the understanding of reality, with reference to authors not only geography, but also maintained dialogue with economists and sociologists. Seek so to evidence the specificities of the ongoing process that more closely affect the productive process, the relations and work organization, especially in rural areas, performing a general analysis about the Paradigm of Flexible Accumulation, in order to situate the particularities in whole in inside which is defined your presence, as a case study disjointed of the all of is able to cloud the understanding of the actual process.

Key words: Restructuring of the production and of the space, labor relations, Globalization of Capital.

\section{Resumen}

El presente artículo constituí la análisis de las dimensiones de la actual fase de expansión mundial de capitalismo, que es: la reestructuración productiva y consecuentemente espacial en curso. La dinámica del desarrollo capitalista es provocando transformaciones- en la economía, en las relaciones sociales, en la política, en la cultura y, en el mundo del trabajo también están operando cambios cuantitativos y cualitativos. Procuramos proporcionar una clara comprensión del instrumento lógicoconceptual en que apoyarse la presente análisis. Por tratarse de una análisis multidisciplinar, la abordaje de la temática exigió el recurso la uno cuerpo teórico que forneciese la comprensión de la realidad, tiendo como referencia autores no solamente de la geografía, como también mantuvimos diálogos con economistas y sociólogos. Buscamos así evidenciar las especificidades del proceso en curso que más cerca afectan lo proceso productivo, las relaciones y organizaciones del trabajo, notablemente en el espacio rural, haciendo una análisis general acerca de paradigma de la acumulación flexible conociendo las particularidades en el total donde é definido su presencia, ya que uno estudio de caso desarticulado del total es capaz de turbar la comprensión del proceso real.

Palabras-claves: Reestructuración de la producción y del espacio, relaciones de trabajo, mundialización del capital.

\section{Introdução}

A presente pesquisa analisa os impactos do processo de reestruturação produtiva e espacial sobre a atividade agrícola, tendo como objetivo delinear as principais alterações que ocorrem no trabalho agrícola.

A ampliação dos sistemas de objetos ligados à produção e reprodução da força-de-trabalho, acarretou modificações no mercado de trabalho, interferindo diretamente na dinâmica socioespacial. 


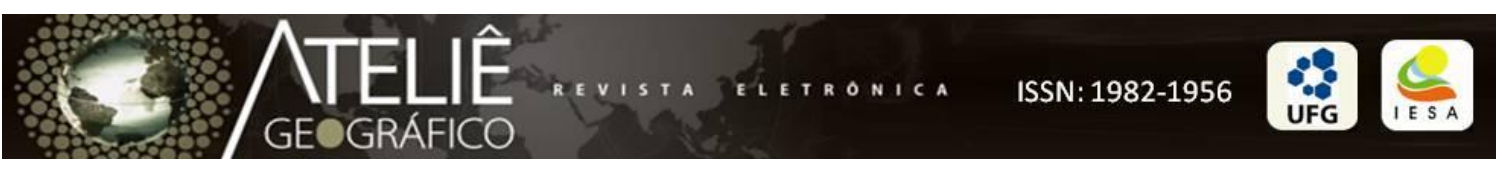

Desta forma, analisamos a estrutura, especificidade e dinâmica do trabalho agrícola, sublinhando as tendências recentes, o que permitiu traçar um cenário do trabalho agrícola diante do processo de reestruturação produtiva.

Partindo do pressuposto de que para desvendarmos como as mudanças na estrutura produtiva contribuem para explicar os impactos sobre o trabalho agrícola é preciso tornar inteligível esse processo em diferentes escalas, optamos por uma delimitação espacial tendo por base um estudo no Baixo Jaguaribe.

A escolha do Baixo Jaguaribe como objeto de estudo se deveu ao destaque desta região no espaço cearense, no que se refere às metamorfoses na estrutura produtiva e espacial em curso nas últimas quatro décadas, reflexo das políticas públicas e privadas que criam as condições favoráveis para a reprodução ampliada do capital.

Apesar da necessidade de delimitar a área em que o fenômeno se manifesta para facilitar o estudo, sabemos que, a espacialidade dos fenômenos, matéria-prima da Geografia, é possível ser observada em diversas escalas que são intrinsecamente relacionadas, sendo quase impossível analisá-las separadas e fragmentadas, pois se interrelacionam e interpenetram.

Buscamos, assim, estudar as recentes transformações que, de uma forma mais geral, dizem respeito ao modo de produção capitalista no atual processo de mudanças na economia mundial e que se desdobram em redefinições no mundo do trabalho.

Para encaminhamento deste trabalho, realizamos inicialmente o seguinte questionamento norteador: Quais impactos da reestruturação produtiva no trabalho agrícola?

$\mathrm{Na}$ busca de responder a este questionamento, foi possível compreender as transformações nas relações sociais de produção, como também as mutações que operam no espaço, já que a realização da produção se dá através da produção social e espacial.

Foi possível investigar como a oferta e a demanda de mão-de-obra têm se ajustado diante das exigências do agronegócio, além de identificar as relações de trabalho vigentes no processo produtivo da atividade agrícola, os novos postos de trabalho que estão sendo criados no campo, as novas qualificações exigidas e verificar o 
nível do emprego agrícola, revelando o papel da agricultura, motor da economia no Baixo Jaguaribe, na absorção de mão-de-obra.

Diante disto, o Baixo Jaguaribe foi considerado um universo capaz de responder o questionamento ao qual nos referíamos anteriormente, sendo a abrangência temporal da análise o período que vai da década de 1970 até a década atual.

A pesquisa bibliográfica, estatística e de campo nos permitiu apontar tendências e desafios e obter um quadro representativo das transformações em curso na atividade agrícola.

Como a análise do impacto da reestruturação produtiva sobre a atividade agrícola não poderia estar desvinculada da atual etapa de acumulação capitalista, visto que, a expansão capitalista se efetiva, dentre outras coisas através do processo de reestruturação da produção e do trabalho, procuramos inicialmente realizar uma contextualização da materialização do processo de reestruturação produtiva. Posteriormente analisamos como o Baixo Jaguaribe se insere no contexto mundial para responder às necessidades apresentadas pela produção moderna, procurando entender como vem se dando o processo de reestruturação produtiva no Baixo Jaguaribe que tem sua base na política de modernização assentada na agricultura irrigada, o que nos remeteu às mudanças operadas no espaço agrário, bem como seus reflexos na força-detrabalho.

Para tanto, se faz necessário esboçar algumas evidências, análises e considerações, a seguir:

\section{A reestruturação produtiva na era da mundialização do capital}

Em um cenário mundial de concorrência capitalista, a busca pelo aumento da produtividade e o restabelecimento das estruturas de acumulação é o que impulsiona as unidades produtivas a executarem modificações nos processos de trabalho, acelerando a inserção de inovações tecnológicas no processo produtivo, cuja expressão tem sido "a microeletrônica, a automação, a robótica, a informática e as redes que aceleram e multiplicam a capacidade produtiva da força-de-trabalho" (IANNI, 1997, p.157). 
Paralelamente às inovações vêm sendo implementadas novas políticas de gestão da produção e de organização do trabalho, em que se observa a introdução de procedimentos organizacionais globais: kaban, just-in-time, a série de racionalizações da produção, tais como os downsizing e a reengenharia, os programas de qualidade total que possibilitaram o gerenciamento do trabalho via círculos de controle de qualidade e gestão participativa que permitem uma maior economia de espaço, tempo de produção, maior controle de qualidade do produto e consequentemente maior produtividade.

Em nome da competitividade e majoração da taxa de lucros, o que presenciamos é a "flexibilização" das leis trabalhistas, tornando-se a terceirização uma prática comum, um dos pilares do atual modelo produtivo, o que em outros termos significa excluir uma crescente massa de trabalhadores do gozo de seus direitos legais, resultado de conquistas históricas contidas na legislação trabalhista, cuja existência passa a ser denunciada como obstáculo à expansão do emprego formal (ANTUNES, 1997).

Com o "regime de acumulação sob a dominância do capital financeiro" denominado de mundialização do capital (CHESNAIS, 1996, p.24), a ciência e a tecnologia a serviço direto da produção e reprodução do capital, invadem os setores produtivos com muito mais ímpeto, inserindo-se nas relações de trabalho, criando um novo ethos para estas relações, uma nova via de racionalização do trabalho adequada às atuais necessidades de acumulação do capital (ALVES, 1999:22).

Cabe aqui ressaltar que optamos por utilizar o conceito de mundialização ao invés de globalização, para diferenciarmos o atual período em que Alves(2001) afirma ser uma nova etapa do desenvolvimento do capitalismo caracterizada pela predominância do capital financeiro no processo de acumulação capitalista. "O que implica em não reduzir a nova etapa de internacionalização capitalista a uma mera continuidade da ocidentalização do mundo iniciada no século XV", ou seja, - "é antes de tudo, a globalização do capital e não a mera globalização das trocas" (ALVES, 1999, p.61). Segundo Santos(2000:23) "nos encontramos em um novo patamar da internacionalização, com uma verdadeira mundialização do produto, do dinheiro, do crédito, da dívida, do consumo, da informação".

Nesse contexto, a mundialização do capital tendeu a impulsionar o processo de reestruturação produtiva, uma vez que ao demandar transformações na estrutura 
produtiva, difundindo a modernização dos processos de trabalho e produção, a mundialização permitiu o aprofundamento do processo de reestruturação, resultando na reterritorialização ou recuperação político-territorial do poder de trocas globais para obtenção de vantagens competitivas entre as nações.

A reestruturação produtiva assentada na divisão do trabalho entre unidades produtivas integradas espacialmente articula-se, portanto, às duas faces da mesma moeda, uma diz respeito à crise do capitalismo, tendo sido uma resposta ao esgotamento do padrão de crescimento econômico capitalista até então vigente - fordismo, e, por conseguinte, da redução da taxa de lucro, a outra ao processo de mundialização do capital, uma vez que para adequar a economia ao mercado global, havia necessidade de se reestruturar o modo pelo qual se organizava a produção, distribuição e consumo (cadeia produtiva como um todo) que, por sua vez, passou a ser uma determinação do novo regime de acumulação capitalista, como novo paradigma tecnológico/organizacional cuja característica essencial pode ser resumida em uma palavra, qual seja: flexibilidade (HARVEY, 1993).

Com o advento de um novo paradigma tecnológico e produtivo e uma nova organização do trabalho, o capitalismo começa a se remodelar, redefinindo e reestruturando o processo de acumulação e regulação de sua economia, através da exploração mais intensiva de capital e de trabalho, da produção flexível e do desacionamento do Estado-Providência (Welfare State).

Conforme Soja:

“[...] a reestruturação, em seu sentido mais amplo, transmite a noção de uma ruptura nas tendências seculares, e de uma mudança em direção a uma ordem e uma configuração significativamente diferentes da vida social, econômica e política. Evoca, pois, uma combinação seqüencial de desmoronamento e reconstrução, de desconstrução e tentativa de reconstituição [...]" (SOJA, 1993, p. 193).

A atual fase do processo de reestruturação produtiva coincide com a passagem do capitalismo industrial para o capitalismo financeiro ou monopolista. Iniciada no Brasil já na segunda metade da década de oitenta do século $\mathrm{XX}$, acelera-se rapidamente a partir dos anos noventa, quando ocorre a abertura da economia durante o governo Collor. 


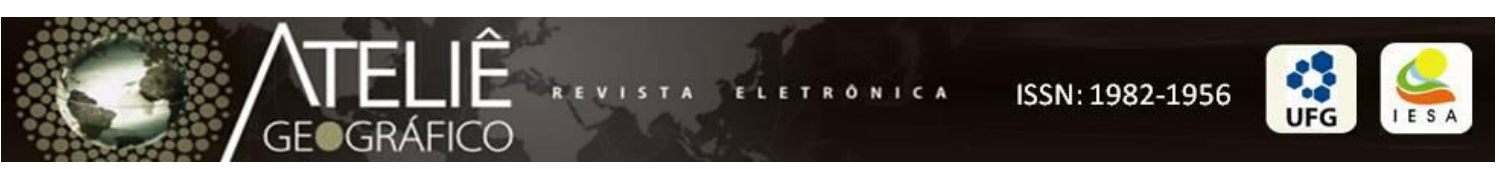

Esse processo se aprofundou com a política de estabilização implementada a partir do Plano Real, no governo Cardoso em 1994, com a subvalorização do dólar frente ao real e uma grande facilidade para importação, que exigiu das empresas transformações em ritmo acelerado e associações com capitais estrangeiros, para poderem sobreviver.

Sendo a reestruturação produtiva um viés da reestruturação do capital que tem impacto em todas as esferas da sociedade. Podemos afirmar que na passagem do capitalismo comercial para o capitalismo industrial ocorre a primeira fase da reestruturação produtiva sob o signo da modernidade. Esta fase, quando ganham terreno as idéias liberais, perdura até a crise de 1929 que se tornou mundial e abalou todo o sistema capitalista, entrando em cena o Estado do Bem-Estar Social. Como resposta à crise do modelo Keynesiano-Fordista temos a segunda e atual fase da reestruturação capitalista com a passagem do capitalismo industrial para o capitalismo financeiro que se caracteriza, dentre outras coisas, pela união do capital comercial, industrial, agrário e bancário sob o signo da pós-modernidade, com o predomínio de um novo padrão de acumulação capitalista - a acumulação flexível, sob o impulso das políticas neoliberais na era da mundialização do capital.

Ratificamos que assim como a revolução ocorrida durante o capitalismo industrial foi impulsionada pela busca do aumento da produtividade e o restabelecimento das bases para a acumulação capitalista, em um cenário mundial de concorrência capitalista, isto também é o que impulsiona as rápidas mudanças dos padrões de crescimento. Isto ocorre em diferentes setores da economia que na produção de seus produtos específicos são setores de valorização do capital. Dizemos em diferentes setores da economia porque distintamente das sociedades anteriores que exploravam sucessivamente a caça, a criação, a agricultura, o mercado, a indústria, a atual fase do capitalismo não se apóia mais sobre um único setor, mas sobre uma rede de setores, estando os agentes sociais, direta ou indiretamente, integrados em corporações, ou, mesmo, configurando o que Gottdiener(1993, p.218) denomina "redes de crescimento".

\section{Impactos da reestruturação na atividade agrícola}


Embora os estudos sobre a reestruturação produtiva no Brasil venham sendo realizados, principalmente, no setor industrial, sendo minoritárias as pesquisas que têm investigado o setor primário, o processo de reestruturação produtiva não permanece no plano das indústrias, mas invade o campo onde a racionalidade perversa se instala mais rapidamente por este ser mais suscetível à difusão do capital do que a cidade. A cidade deixa de ser o locus por excelência dos capitais novos ${ }^{1}$ porque a paisagem urbana reúne e associa pedaços de tempo materializados de forma diversa, ao contrário do campo, prenhe de espaços virgens, "livre de heranças de diferentes sistemas técnicos e sociais, de modo que o novo vai se dá com maior velocidade e rentabilidade". Ainda assim, "a cidade, sobretudo nas áreas mais fortemente tocadas pela modernidade, é o lugar da regulação do trabalho agrícola" (SANTOS, 1994, p.138; 104).

No espaço rural a reestruturação produtiva se faz presente, notadamente na atividade agrícola moderna, onde o processo de reestruturação impulsiona a substituição da base técnico-científica que dá origem a uma nova "configuração territorial formada pelo conjunto de sistemas de engenharia que o homem vai superpondo à natureza, verdadeiras próteses, de maneira a permitir que se criem as condições de trabalho próprias de cada época" (SANTOS, 1994, p.141).

$\mathrm{Na}$ busca de alcançar um padrão de competitividade mais elevado a atividade agrícola passa por consideráveis alterações na sua estrutura organizacional de produção, dentre as quais podemos citar: os sistemas técnicos (SANTOS, 1994, 1996) de irrigação, transportes, eletrificação, armazenagem e telecomunicações, a difusão das inovações mecânicas(arados de tração mecânica, tratores e colheitadeiras), físicoquímicas(corretivos, fertilizantes, agrotóxicos) e biotecnológicas, cuja expressão maior é o advento de uma nova força produtiva, a biotecnologia, que dirige as inovações a partir da engenharia genética através da transferência de genes, modificando decisivamente as características dos animais e vegetais e as variedades geneticamente melhoradas daí resultantes passam a comandar de forma decisiva o calendário agrícola (SILVA, 1981).

\footnotetext{
${ }^{1}$ Estes capitais novos é que dão a direção dos processos em curso na agricultura brasileira e podem ser medidos pelos fixos e fluxos (SANTOS, 1988:77) que acarretam novas formas tecnológicas, organizacionais e ocupacionais.
} 
Dentre as inovações que ocorrem na agricultura (química, mecânica e biotecnológica) a que tem um impacto mais direto sobre o trabalho são as inovações mecânicas. Estas reduzem o tempo de trabalho e o número de trabalhadores por hectare cultivado, ao mesmo tempo em que provocam o aumento da produtividade do trabalho através do aumento da intensidade e do ritmo da jornada de trabalho. Já as inovações físico-químicas elevam a produtividade da terra e as inovações biotecnológicas reduzem substancialmente o ciclo biológico do processo natural de produção.

O impacto maior da reestruturação produtiva na agricultura se dá sobre o trabalhador braçal que vem se tornando cada vez mais dispensável ao processo produtivo agrícola. É o homem rústico, dotado de segredos e saberes adquiridos ao longo do exercício da atividade agrícola que está sendo substituído, ou "melhor" dizendo, que continuamente perde espaço neste novo contexto, já que suas chances de conseguir trabalho são cada vez menores.

É inegável que o processo de reestruturação em curso permite, entre outras coisas, reduzir ao mínimo o desgaste na realização dos trabalhos agrícolas, que os métodos tradicionais impunham, aproveitar melhor a área ocupada pelas culturas através de uma exploração mais intensiva, aumentar de forma espetacular o rendimento do trabalho e as consequentes produções. No entanto, não podemos desprezar alguns aspectos negativos, também decorrentes desse processo, notadamente os que envolvem a redução do nível de emprego e intensificação da sazonalidade do trabalho agrícola que é, por sua própria natureza, sazonal e descontínuo.

Diante disto, podemos afirmar que além da eventualidade das tarefas laborais que necessitam do trabalhador agrícola, a reestruturação produtiva vem causando um aumento na sazonalidade da demanda por trabalhadores agrícolas devido a introdução de técnicas modernas não ter atingido todas as fases do ciclo produtivo, especialmente a fase da colheita, que é uma das mais exigentes em termos de mão-deobra. No caso da fruticultura atingiu principalmente a preparação do solo, pois nas atividades relacionadas com os tratos culturais e de colheita permanece o trabalho manual. Como exemplo, temos a cultura do melão que mesmo dispondo de todo aparato tecnológico necessita de um maior número de trabalhadores na fase da colheita sendo a maioria dispensada nas demais etapas do processo produtivo. Por outro lado, já podemos vislumbrar a existência de colheitadeiras na cultura do abacaxi, por parte da 
transnacional Del Monte, mas mesmo reduzindo o quantitativo de trabalhadores e contribuindo para o desemprego tecnológico, o uso deste maquinário não dispensa o trabalho manual que é indispensável no corte e colocação do abacaxi nos braços da máquina que alcança o estreito espaço que os trabalhadores conseguem ocupar para colher o abacaxi.

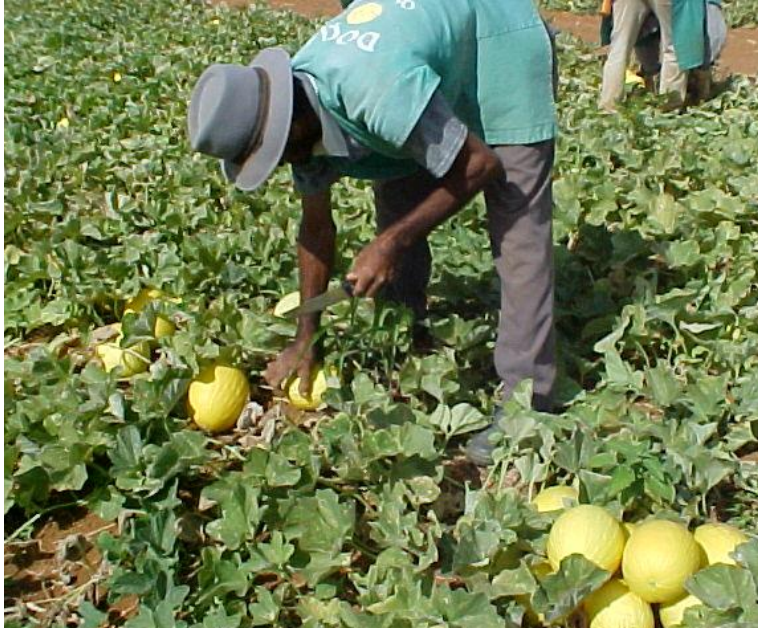

Figura 01- Colheita do melão - Quixeré Autora: Alexsandra Muniz, 2004

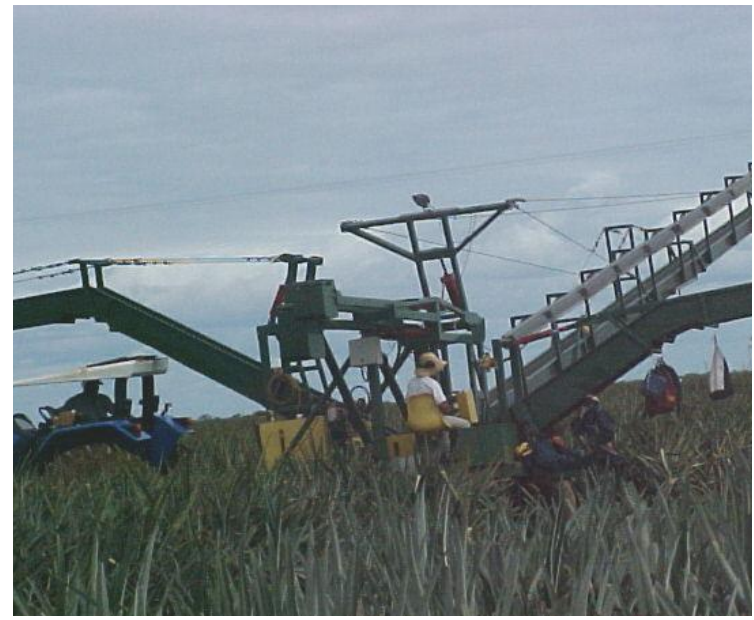

Figura 02 - Colheitadeira - Del Monte/Limoeiro do Norte. Autora: Alexsandra Muniz, 2004

Destarte, o processo de reestruturação vem determinando necessidades decrescentes ou localizadas em espaços de tempo muito específicos da mão-de-obra sem maior especialização possibilitando que o emprego temporário se torne mais vantajoso para o empregador.

O processo de reestruturação produtiva no meio rural ocasiona um reordenamento nas forças produtivas, nas relações de trabalho e, sobretudo, no espaço. O Ceará, até então visto pelo problema da seca, ganha atenção especial, transformandose em espaço de oportunidades para investimento do capital. O governo federal objetivando dar continuidade às políticas de desenvolvimento econômico implementadas com a intervenção planejada do Estado a partir dos anos 1960, ao mesmo tempo em que reduzia os gastos públicos, passou a maximizar a oferta de fatores locacionais, capazes de atrair os investimentos privados. É então no contexto da guerra fiscal entre os Estados denominada por Santos e Silveira (2001) como a "guerra dos lugares" que os incentivos para o Ceará nos anos 1990 são ampliados para setores como 
o turismo e o agronegócio de exportação com base na agricultura irrigada (fruticultura, horticultura, floricultura) e na agroindústria a ela associada.

No Baixo Jaguaribe, em particular, com o destaque ao agronegócio da fruticultura irrigada, isto pode ser visto tanto no Perímetro Irrigado Jaguaribe-Apodi, onde os produtores passam a ser micro e grandes empresários e a propriedade passa a ser uma empresa rural, como também nas agroindústrias e empresas agrícolas (nacionais e transnacionais) instaladas em Quixeré em que empresários juntamente com pequenos produtores-irrigantes (microempresários) passam a vender para outros Estados do espaço nacional e as empresas de maior porte (maior escala de produção, maior capacidade inovativa, como: logística, marca ou tecnologia) alcançam espaços cada vez mais longínquos, indo além das porteiras. Além disto, adotam mudanças que dizem respeito aos novos métodos de produção e às novas formas de organizar e gerir o trabalho.

Mesmo apresentando vantagens comparativas como atrativo para investimentos de capital intensivo, por ser parte do território cearense, nesta região também predomina o uso de técnicas de baixa produtividade, mas a alta fertilidade dos solos e a facilidade na obtenção de água na planície aluvial favoreceram seu grande aproveitamento agrícola, fato que justifica a valorização deste espaço não somente a partir da política de irrigação, mas desde a ocupação do Vale do Jaguaribe, onde historicamente se desenvolveu a pecuária e a agricultura irrigada.

A região do Baixo Jaguaribe está inserida no semi-árido do Estado do Ceará, localizando-se a nordeste deste, no quadrante das coordenadas geográficas de $5^{\circ}$ $06^{\prime}$ e $5^{\circ} 31^{\prime}$ de latitude sul e $37^{\circ} 46^{\prime}$ e $38^{\circ} 22^{\prime}$ de longitude oeste. De acordo com a divisão político-administrativa do IBGE (Instituto Brasileiro de Geografia e Estatística) esta região limita-se ao norte com o município de Beberibe, ao sul com os municípios de Iracema e Potiretama, a oeste com os municípios de Ibaretama, Quixadá e Banabuiú e a leste com o Rio Grande do Norte.

O Baixo Jaguaribe ocupa uma área de $9.791 \mathrm{Km}^{2}$, que corresponde a cerca de $6,8 \%$ do território cearense, representada por $10(\mathrm{dez})$ dos 184(cento e oitenta e quatro) municípios cearenses, quais sejam: Alto Santo, São João do Jaguaribe, Ibicuitinga, Morada Nova, Tabuleiro do Norte, Limoeiro do Norte, Quixeré, Russas, Jaguaruana e Palhano. 


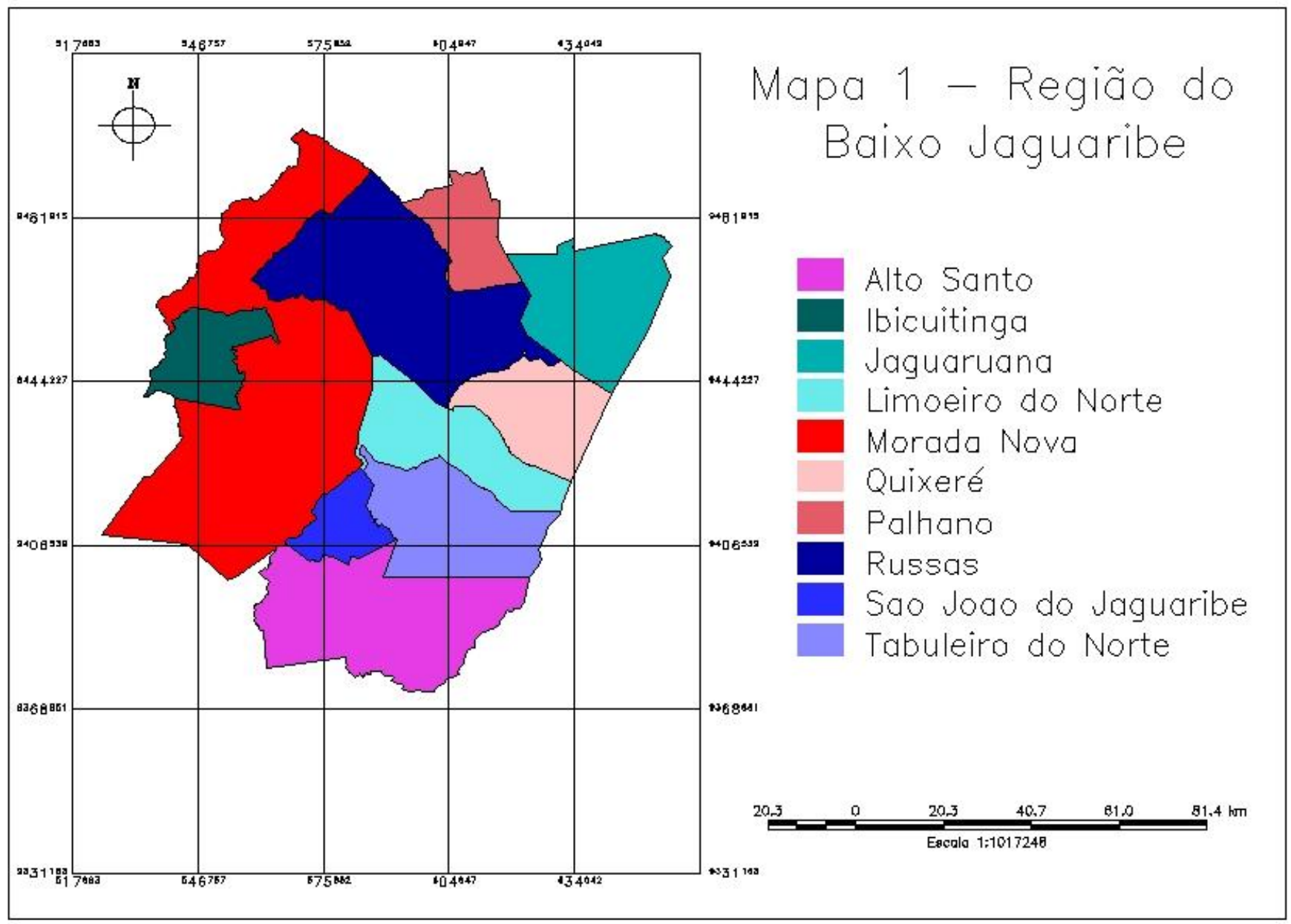

Mapa 1: Municípios constituintes da Região do Baixo Jaguaribe Autora: Alexsandra Muniz, 2004

Vale ressaltar que assim como no espaço cearense, no Baixo Jaguaribe a reestruturação ocorre de forma parcial, heterogênea, descontínua no tempo e no espaço, sendo alguns municípios mais intensamente atingidos, e, mesmo nestes municípios, a reestruturação se materializa em áreas espacialmente restritas, ocorrendo uma segregação dos espaços da produção.

No Baixo Jaguaribe, notadamente nos municípios que vem sendo inseridos de forma mais intensa pelo processo de reestruturação produtiva e espacial (Limoeiro do Norte e Quixeré) ocorre um crescente mercado de trabalho agrícola formal em torno dos novos processos de trabalho, uma vez que os proprietários rurais e empresários agrícolas procuram reter no estabelecimento aqueles trabalhadores dotados de alguma especialização. 
Apesar das distintas demandas por força-de-trabalho durante a atividade agrícola é crescente a necessidade de profissionais especializados. Como afirmou Gonzales e Bastos (1979, p.34) a variação da demanda por mão-de-obra nas diferentes etapas do processo de produção subdivide-se em dois momentos "um momento de alta intensidade de demanda de mão-de-obra, especialmente em determinadas colheitas e, outro menos intenso, onde se mantêm constantes alguns trabalhadores especializados como tratoristas, maquinistas etc".

Dentre os profissionais especializados que evidenciamos durante pesquisa de campo no Baixo Jaguaribe, temos o profissional especializado em: análise do solo, assistência técnica, manejo de irrigação, tratamento fitossanitário, medidas de proteção ambiental, uso adequado de defensivos, enxertia, saneamento, eletromecânica, elaboração de proposta para obtenção de crédito bancário, produção, coleta e seleção de sementes e mudas com melhor potencial de mercado, consultoria de alimentos. Além do engenheiro de segurança do trabalho, engenheiro agrônomo, veterinário, zootecnista, administrador agrícola, tratorista, engenheiro hidráulico, extensionista, tecnólogo, técnico agrícola, operador em geral, inspetor de qualidade, médico do trabalho, entre outros.

Com a presença destes profissionais temos no meio rural o surgimento de um novo proletariado rural. Neste sentido, podemos afirmar que a reestruturação não só destrói empregos, mas também cria novas profissões, embora em proporções bem menores do que as necessidades do mercado de mão-de-obra disponível.

Ocorre assim, a mobilidade populacional nos dois sentidos, pois ao mesmo tempo em que se desloca para o campo uma mão-de-obra especializada, esse processo leva à expulsão daqueles que não conseguiram responder às exigências da nova maneira de produzir. Isto vem reforçar a importância da Geografia na apreensão do trabalho agrícola através do espaço geográfico.

A presença do agrícola não rural (SANTOS, 1993) na cidade expressa a unificação do mercado de mão-de-obra não qualificada, pois além daqueles citadinos que vivem do trabalho que não exige qualificação, juntam-se os que vêm do campo que dominam o conhecimento empírico, mas que são em sua grande maioria analfabetos. $\mathrm{O}$ mesmo ocorre no campo com a vinda do homem urbano, para trabalhar junto com os agrícolas rurais, expressando a migração descendente (SANTOS, 1993) e a alternância 
dos empregos temporários urbanos e rurais quer seja do trabalhador individual quer seja dos membros da família, daí Santos (1988) afirmar que estes dois mercados de trabalho tendem a se confundir. A formação desse mercado de trabalho urbano-rural revela novos conteúdos da relação entre o campo e a cidade.

Diante da expansão do trabalho intelectual no campo, associado, em grande medida, às novas necessidades apresentadas pela produção moderna, temos como consequência a construção de todo um aparato institucional voltado ao ensino técnico e profissionalizante, como exemplo, destacamos a presença do IFCE - Instituto Federal de Educação, Ciência e Tecnologia do Ceará com um campus em Limoeiro do Norte, dos Centros Vocacionais Tecnológicos - CVTs, das Escolas Agrícolas, da Unidade Avançada de Russas que juntos vêm facilitando a difusão do conhecimento, além do aumento da produção e produtividade, a redução de custos e a inserção competitiva no mercado global, uma vez que a capacitação não se restringe aos aspectos de produção, mas se estende aos aspectos de gestão e pós-colheita.

Ao contrário do assalariado formal e sindicalizado que predomina na Chapada do Apodi e nas agroindústrias, nas demais áreas da região predomina o emprego informal, ou seja, aquele que não segue as normas da legislação trabalhista, sendo o trabalhador pago na maioria das vezes na forma de diária ou empeleita ${ }^{2}$.

Cabe ressaltar que não estamos considerando a reestruturação produtiva como a causa da presença do trabalhador assalariado temporário, pois se assim fosse estaríamos afirmando que a reestruturação no Baixo Jaguaribe ocorreu muito antes do que se imagina, já que o trabalho assalariado temporário ganha dimensão no campo, especialmente após 1963. Porém, é importante salientarmos que estamos falando de uma das manifestações do processo em curso que é a intensificação do trabalho agrícola informal, já uma característica no espaço agrícola, na figura do trabalhador assalariado temporário, do diarista, do alugado, parceiro, dentre outros.

Na região do Baixo Jaguaribe foi possível constatar que esta informalidade é mais presente no trabalho braçal, ou seja, dentre aqueles que não têm capacitação, mas que detêm experiência empírica, fato oposto foi o que verificamos naqueles com maior nível de instrução e especialização, pois em sua maioria possuem registro em carteira.

\footnotetext{
2“Empeleita", termo bastante utilizado na linguagem do sertanejo, significa "empreita", "empreitada". Conforme Ferreira (1995) o termo "empreitada", quer dizer trabalho ajustado para pagamento global, e não a dias.
} 
Sendo assim, o perímetro irrigado Jaguaribe-Apodi, a irrigação privada, os médios e grandes estabelecimentos rurais, as empresas agrícolas e as agroindústrias passam a ser o espaço de concentração da classe trabalhadora assalariada tanto permanente quanto temporária, com o trabalho sendo realizado tanto informalmente na forma de diária ou empreita, quanto formalmente seguindo as normas da legislação trabalhista.

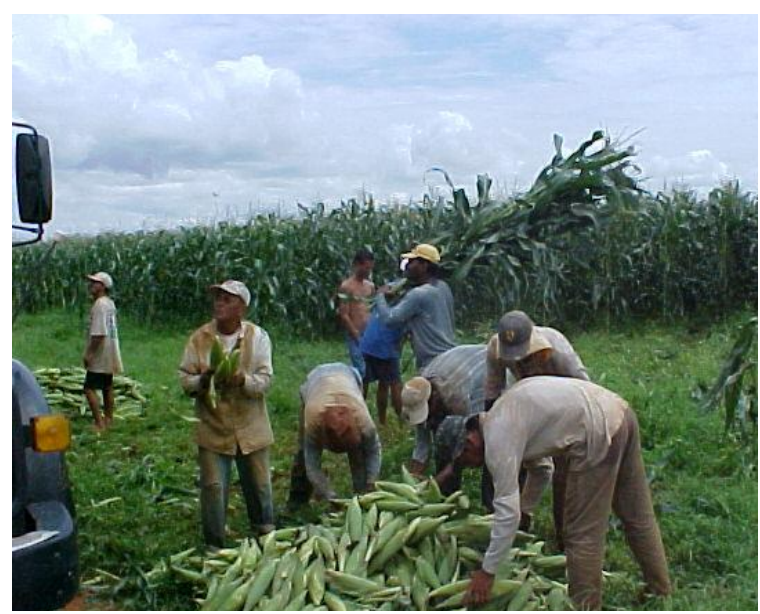

Figura 3 - Trab. formais - Del Monte/Limoeiro do Norte. Autora: Alexsandra Muniz, 2004

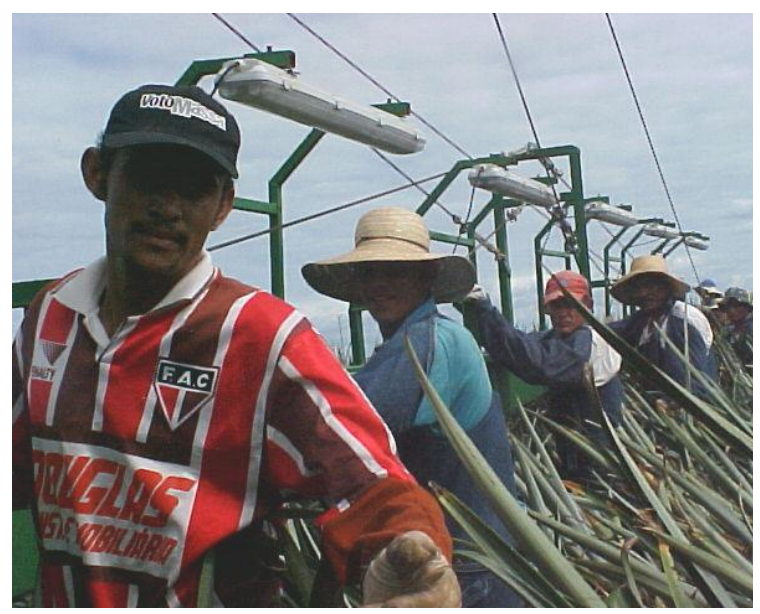

Figura 4 - Trab. informais - Empreiteiros - Faezo PIJA). Autora: Alexsandra Muniz, 2004

Em síntese, nos espaços onde o processo de reestruturação capitalista se dá de forma contínua predomina as relações de trabalho capitalistas (assalariado permanente e temporário, com traços do "novo" - trabalhador agrícola formal e do "velho" - assalariado agrícola informal privado dos direitos estabelecidos pela legislação trabalhista), ao contrário, nos espaços onde esse processo ocorre de forma descontínua mesclam-se as relações de trabalho capitalistas e não capitalistas.

Portanto, não há uma tendência generalizante e uníssona quando se pensa o mundo do trabalho, o que ocorre é um processo contraditório e multiforme. O próprio surgimento de um novo grupo social, representado pelos irrigantes ${ }^{3}$ dos perímetros irrigados, pode se configurar como diferentes formas de reprodução "do 'velho' no 'novo' que propicia condições para a expansão do 'velho', ao mesmo tempo em que o

\footnotetext{
${ }^{3}$ Embora os irrigantes não representem uma categoria de trabalho agrícola, já que são proprietários de terras, mesmo não detendo o título destas, podem se metamorfosear em assalariados temporários, diaristas ou empreiteiros, visto que, sendo minifundistas podem se assalariar temporariamente, empregar mão-deobra ou utilizar somente o trabalho dos membros da família.
} 
próprio 'velho' ressurge modificado, nas suas relações com o 'novo' "(OLIVEIRA, 1975 apud SILVA, 1978).

A crescente disponibilidade de força-de-trabalho desprovida de meios de produção aliado ao aumento do volume de capital nas mãos dos empresários agrícolas, evidencia a sujeição do trabalho e das modalidades tradicionais de produção ao capital.

Sabemos que a necessidade por mão-de-obra na atividade agrícola é bastante variável, tanto segundo o tipo de cultura, a fase do processo produtivo e quanto a atividade a ser executada, o que reflete também quanto à demanda por gênero. Segundo dados da RAIS, no mercado de trabalho formal do setor agropecuário do Baixo Jaguaribe o número de trabalhadores do sexo masculino excede o de mulheres.

Tabela 1 - empregos existentes na agropecuária do Baixo Jaguaribe em 31/12 por sexo, segundo o ramo de atividade -2002

\begin{tabular}{lrrrrrrrr}
\hline & \multicolumn{2}{c}{ Lavouras Temporárias } & \multicolumn{2}{c}{ Lavouras Permanentes } & \multicolumn{2}{c}{ Pecuária } \\
\hline \multicolumn{1}{c}{ MUNICÍPIOS } & \multicolumn{1}{c}{ Masculino } & Feminino & Masculino & Feminino & Masculino & Feminino \\
\hline \hline Alto Santo & 13 & 2 & 0 & 0 & 0 & 0 \\
Jaguaruana & 220 & 7 & 0 & 0 & 0 & 0 \\
Limoeiro do Norte & 32 & 4 & 167 & 6 & 0 & 0 \\
Quixere & 316 & 70 & 1.686 & 270 & 0 & 0 \\
Russas & 1 & 0 & 0 & 1 & 6 & 0 \\
Sao Joao do Jaguaribe & 2 & 0 & 0 & 0 & 0 & 0 \\
Tabuleiro do Norte & 0 & 0 & 2 & 0 & 0 & 0 \\
Total & 58 & 83 & 1.855 & 277 & 6 & 0 \\
\hline \hline
\end{tabular}

Fonte: MTE/RAIS - 2002.

* Os municípios da região que não aparecem apresentaram valores iguais a zero.

Mesmo sendo o contingente de trabalhadores, quantitativamente, mais masculino devido às exigências de determinadas atividades, é notória a crescente presença da mão-de-obra feminina que passa a ser incorporada nas agroindústrias, empresas agrícolas e pequenos e médios estabelecimentos rurais (Figuras 5 e 6). 


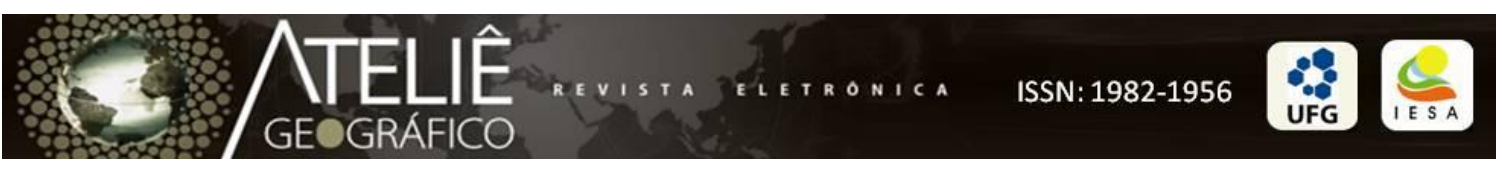

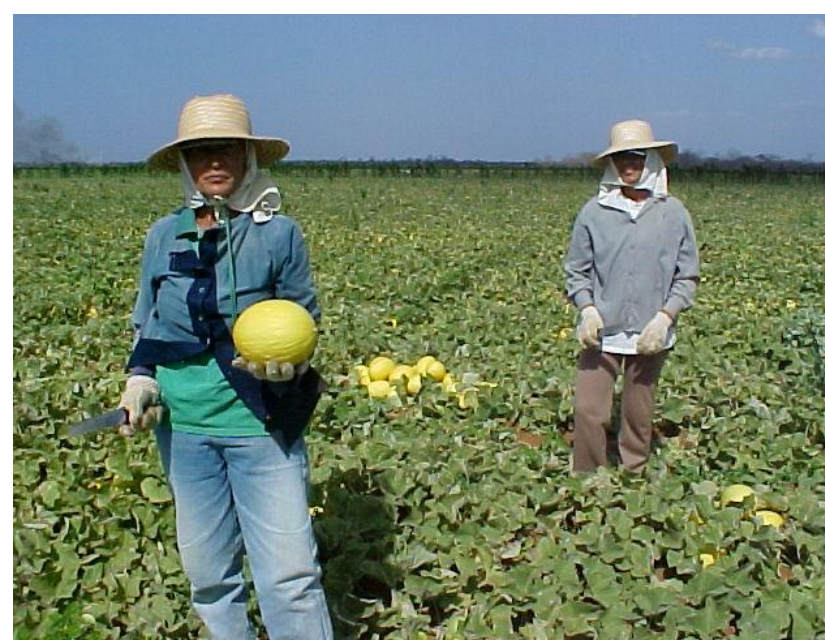

Figura 5 - Trab. agrícolas na colheita do Melão- Quixeré Figura: Alexsandra Muniz, 2004

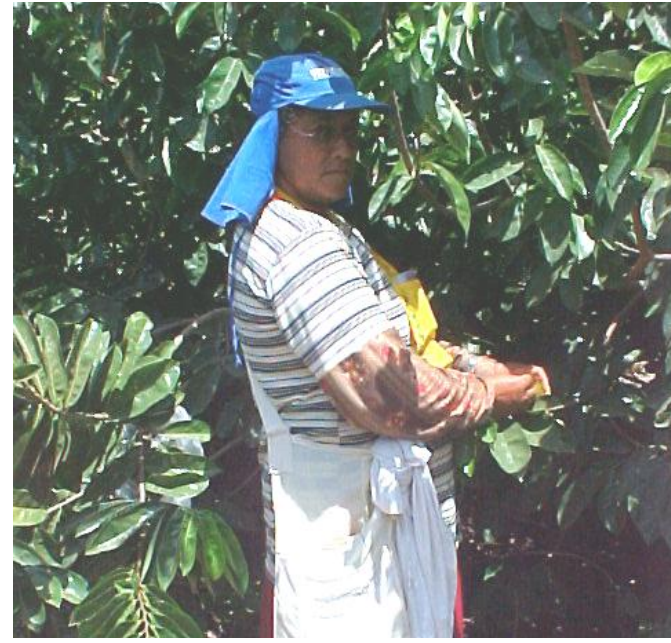

Figura 6 - Trab. Agrícola na Polinização da graviola - Empresa Isratec

Figura: Alexsandra Muniz, 2004

Diante da expulsão da grande maioria dos trabalhadores que o processo de reestruturação produtiva tem provocado, se o trabalhador agrícola já não se ocupava de atividades puramente agrícolas, agora com a crescente articulação entre os diferentes setores e espaços produtivos, este fato torna-se mais evidente. Fora da época da colheita as atividades exercidas pelo trabalhador agrícola assalariado temporário são bastante variadas.

A própria utilização da expressão trabalhador agrícola deve-se ao fato de que nem todo trabalho rural é agrícola, visto que, com a proliferação das agroindústrias e a crescente urbanização do meio rural, este adquire uma heterogeneidade de atividades vinculadas ou não à agropecuária, como é o caso das atividades não-agrícolas ligadas à prestação de serviços, o comércio, e, a indústria que tem como locus não mais somente as zonas urbanas (SILVA, 1996; 1999).

Dentre outras mudanças decorrentes da reestruturação produtiva sobre a PEA (População Economicamente Ativa), constatamos através da análise comparativa dos dados estatísticos do IBGE no período de 1970 a 2000 que a região do Baixo Jaguaribe acompanha a tendência mundial, qual seja: o crescimento da PEA no setor de serviços, apresentando: 
Tabela 2 - população economicamente ativa por ramo de atividade no Baixo Jaguaribe (1970-2000)

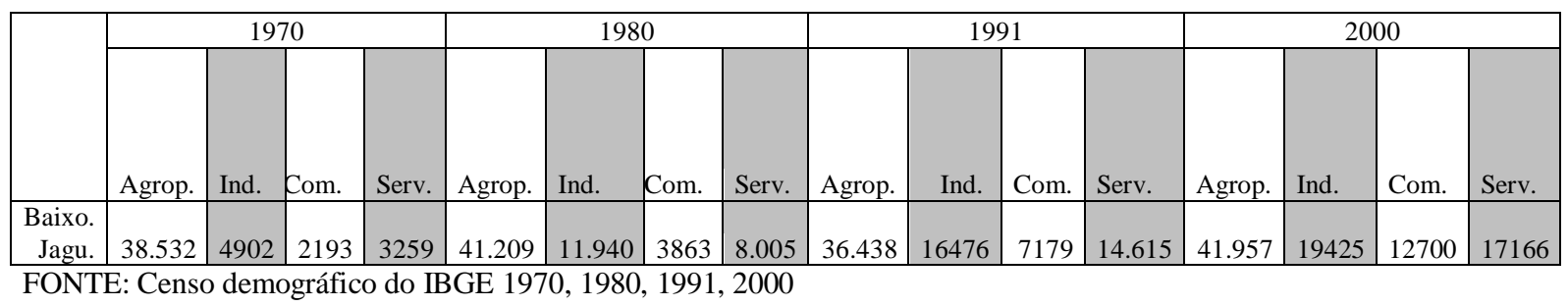

Isto pode ser explicado pelo fato de serem crescentes os serviços diretamente ligados à atividade agrícola e dela derivados, engendrando um quadro favorável ao aparecimento das cidades do campo (SANTOS, 1988). Em Limoeiro do Norte isto é visível dado os investimentos públicos (perímetros irrigados JaguaribeApodi e de Morada Nova que também inclui parte do município de Limoeiro do Norte) e privados (presença de empresas agrícolas e agroindústrias) que demandam tanto serviços voltados ao consumo produtivo(Ibidem) como ao consumo consumptivo(Ibidem) para atender às necessidades da agricultura científica (SANTOS, 2000; ELIAS, 2003b).

Quanto às atividades não agrícolas no meio rural, autores como SILVA (1999) nos apresenta uma leitura nessa perspectiva. Todavia, o deslocamento de trabalhadores para atividades não-agrícolas já encontrava suas primeiras referências na obra de Kautsky - "A Questão Agrária”, no capítulo VIII da referida obra, intitulado 'A Proletarização dos Camponeses', onde este autor estabelece o que denomina de trabalho acessório ou ocupação acessória, referindo-se às situações em que o camponês busca suplementar ou complementar o atendimento de suas necessidades crescentes.

Presenciamos uma maior integração da agricultura com os demais setores econômicos, uma vez que com o desenvolvimento da irrigação investimentos estão sendo realizados a montante e a jusante da produção, produzindo impacto no desenvolvimento de setores não-agrícolas da economia, tais como o comércio, na medida em que provê um mercado para a produção industrial de insumos e equipamentos agrícolas com a geração de toda uma gama de serviços correlatos voltados à atividade agropecuária formando um encadeamento entre fornecedores (como as indústrias de insumos agrícolas), produtores, processadores e comerciantes (inclusive os atuantes no mercado de equipamentos e materiais de apoio à produção), 
como exemplo podemos citar a presença de estabelecimentos comerciais voltados ao consumo produtivo (SANTOS, 1988).

Neste percurso, ocorrem mudanças quantitativas e qualitativas que afetam não somente a dinâmica das forças produtivas, mas também a composição e dinâmica da mão-de-obra do campo, configurando-se, desse modo, uma remodelagem no mercado de trabalho agrícola e no espaço.

Entretanto, há também permanências, uma vez que o processo em curso baseia-se, fundamentalmente, na intensa exploração dos trabalhadores que aumentam a produção da riqueza, mas ficam com uma parte cada vez menor do resultado de seu trabalho.

Em suma, assim como na indústria, a reestruturação produtiva também se faz presente na agricultura onde se dá de forma concentrada, trazendo "benesses" referente ao mais rápido processo de acumulação e rotação do capital, mas não ocorre uma distribuição equilibrada dessas benesses, que favorecem uma minoria de grandes empresários rurais, acentuando a geografia das desigualdades.

Em outras palavras, o atual padrão de acumulação, em que pese suas substanciais diferenças, é na verdade uma contínua expansão dos limites impostos à valorização do capital através da renovação dos suportes clássicos de extração do excedente (com o aprofundamento na diminuição do tempo de rotação do capital), ou ainda, através da criação de novas economias de tempo que irão permitir uma diminuição do custo de produção. Por outro lado, traz consigo inúmeros impactos sociais, espaciais e ambientais.

\section{Considerações finais}

Diante do exposto podemos afirmar que a reestruturação produtiva é um viés da reestruturação do capital que não está restrita à economia, tendo repercussões no plano social e se materializa no espaço.

A sucessão de bases técnicas que substituem umas às outras dentro do modo de produção capitalista e que são inerentes à sua lógica e os processos de trabalho que passam a se desenvolver, tão em voga na atualidade, inclusive dividindo espaço com outros modelos existentes, buscam alcançar os mesmos objetivos que os precedentes, 
quais sejam: a superação da crise e a decorrente forma histórica encontrada pelo capital para implementar o processo de continuidade antes que de ruptura. Melhor dizendo, no seu sentido dialético, é uma ruptura no interior da continuidade da lógica de valorização do capital, que não ocorre mais somente através da intensificação da exploração sobre o trabalhador, onde a racionalização do trabalho é levada ao extremo. A extração do excedente ocorre em bases mais amplas que sob o taylorismo ou fordismo, sobretudo através do sistema financeiro, sob o capitalismo mundial, com o impulso das políticas neoliberais.

Dessa maneira, se torna notória a razão pela qual os capitalistas lançam mão dos mais diversos processos de trabalho, qual seja, encontrar a forma mais adequada para intensificar a exploração sobre a classe trabalhadora. Esta é a unidade na diversidade dos processos de trabalho. Levando em conta as profundas diferenças e especificidades que guardam entre si, este é o elemento central na constituição histórica das diversas fases do capitalismo, bem como de seus variados padrões de acumulação, desde o keynesiano-fordista e o padrão que daí vem se originando.

Aquilo que está relacionado à organização da produção (ritmo e intensidade do trabalho, divisão social do trabalho, formas de organização e automação do trabalho) é acionado pelo capital para gerar economias de tempo. Com o aumento da velocidade de rotação do capital, a reestruturação possibilita uma maior capacidade de acumulação por parte de uma minoria.

Para nós, a Reestruturação produtiva se caracteriza não somente pela mudança da base técnica de produção, indo além da racionalidade que se instalou nos objetos de trabalho e no próprio espaço, uma vez que envolve também, a materialidade da classe trabalhadora, ou seja, as diferentes formas de relações de trabalho no espaço, como também sua própria subjetividade.

Uma análise estritamente econômica não pode dar conta da complexidade do processo em curso, ao passo que "as técnicas presentes na fábrica e no escritório ou incorporadas ao próprio solo como infra-estruturas acabam por condicionar as formas de trabalho, as relações sociais e a vida cotidiana" (SANTOS, 2000, p.20), envolvendo modos de ser, pensar, agir e sentir. Todavia foge, aos limites propostos por este trabalho, enfocar a questão do trabalho do ponto de vista da subjetividade do trabalhador. 
Os fatos até aqui expostos corroboraram para afirmar que os impactos da reestruturação produtiva se traduzem, dentre outras coisas, na extrema racionalização do processo de trabalho, na redução do tempo de produção, no aumento da produtividade do trabalho, no dualismo do mercado de trabalho com o desemprego crescente acompanhado do aumento do emprego formal, trabalho assalariado permanente - maior "qualificação", escolarização e maiores salários \& trabalhos instáveis - precários, temporários, "desqualificados" e com níveis de salários inferiores, crescimento da PEA no setor de serviços, em novos requisitos e especialização da força-de-trabalho que acaba gerando o profissional especializado e desqualificado, no surgimento de postos de trabalho, em modificações na estrutura profissional e na equação dos empregos, na intensa mobilidade da força-de-trabalho, maior inserção da mão-de-obra feminina e juvenil, na redução dos índices de sindicalização, na intensa divisão do trabalho, aumento da intensidade e do ritmo da jornada de trabalho. Paralelamente, vem ganhando espaço as terceirizações, a presença de estagiários, o aviltamento das relações de trabalho, denotando as péssimas condições de trabalho, o que significa criar as condições propícias para o aumento da exploração do trabalho, etc.

Considerando que o processo em curso ocorre de forma parcial, heterogênea, descontínua no tempo e no espaço, vale ressaltar que parte considerável do progresso técnico e das mudanças nas relações de produção no espaço rural ocorre onde se concentram os perímetros irrigados, empresas agrícolas e agroindústrias. Estes têm sido o locus da expansão das relações de trabalho capitalistas nos moldes atuais.

Embora novas oportunidades de trabalho estejam surgindo através do cultivo de frutas permanentes e de variedades geneticamente melhoradas que permitem uma produção quase que contínua ao longo do ano agrícola, o mercado de trabalho se apresenta cada vez mais seletivo e o capital investido em máquinas e equipamentos é maior que o capital humano, provocando o desemprego tecnológico ou de exclusão. Perante tal cenário, vislumbramos uma névoa em torno do futuro do trabalhador dotado de experiência e conhecimento empírico, mas que não domina o conhecimento técnico.

Ao invés de impulsionar o desenvolvimento regional, a política de irrigação (baseada na especialização da produção - fruticultura irrigada- e no incentivo à iniciativa privada) que constitui um dos vetores do processo de reestruturação em curso, 
tem permitido a constituição de enclaves, resultantes de intervenções pontuais, que ignoram o que se passa do lado de fora da cerca que separa os oásis do seu entorno.

Um olhar mais amplo sobre os impactos da reestruturação na atividade agrícola permite ver além da geração de divisas a partir do aumento das exportações. Neste contexto, a maneira como grande parte dos pequenos produtores vêm sendo excluídos do processo em curso e a conseqüente expropriação e proletarização deste segmento somada à abundante oferta de mão-de-obra que não tem outra forma de garantir a sua sobrevivência senão pela venda temporária da sua força-de-trabalho são fatores que não podem ser desconsiderados, nem tampouco minimizados.

A necessidade de pesquisas atinentes ao mundo do trabalho e as implicações socioespaciais é o que instiga a continuidade dos estudos referentes à geografia do trabalho.

\section{Referências}

ALVES, Giovanni. Neoliberalismo e Reestruturação Produtiva. As Novas Determinantes do Mundo do Trabalho. São Paulo: Cortez, 1996.

. Trabalho e Mundialização do Capital. Londrina: Práxis, 1999.

. O Novo (e Precário) Mundo do Trabalho. São Paulo: Boitempo, 2000.

. Dimensões da globalização: o capital e suas contradições. Londrina: Práxis, 2001.

ANTUNES, R. Adeus ao Trabalho? . 4. ed. São Paulo: Cortez; Campinas, SP: Editora da Universidade Estadual de Campinas, 1997.

CHESNAIS, François. A mundialização do Capital. São Paulo: Xamã, 1996.

ELIAS, Denise; SAMPAIO, José Levi Furtado.(orgs). Modernização Excludente. Fortaleza: Fundação Demócrito Rocha, 2002. (Coleção Paradigmas da Agricultura Cearense).

ELIAS, Denise.(org.). O Novo Espaço da Produção Globalizada: O Baixo JaguaribeCE. Fortaleza: Funece, 2002b. 
Agricultura Científica no Brasil: impactos territoriais e sociais. In: SOUZA,

M.A.A. de (org.). Território Brasileiro: usos e abusos. Campinas: Territorial, 2003b (p. 315-340).

GOTTDIENER, Mark. A produção social do espaço urbano. São Paulo: EDUSP, 1993.

HARVEY, David. Condição pós-modema. São Paulo: Loyola, 1993.

IANNI, Octávio. A era do globalismo. 3. ed. Rio de Janeiro: Civilização Brasileira, 1997.

KAUTSKY, Karl. A questão agrária. São Paulo: Nova Cultural, Proposta Editorial, 1986.

MARX, Karl. Contribuição à Crítica da Economia Política. 2. ed. São Paulo: Ed. Martins Fontes, 1973.

. O Capital. Livro I, v. 2. Rio de Janeiro: Bertrand, 1989.

MUNIZ, Alexsandra M. Vieira. Reestruturação produtiva e trabalho agrícola no Baixo Jaguaribe. Dissertação (Mestrado) - Universidade Estadual do Ceará, Fortaleza, 2004.

SANTOS, Milton. Metamorfose do espaço habitado. São Paulo: Hucitec, 1988.

. A Urbanização Brasileira. São Paulo: Hucitec, 1993.

- Técnica, espaço, tempo. Globalização e meio técnico-científicoinformacional. São Paulo: Hucitec, 1994.

A natureza do espaço: técnica e tempo. Razão e emoção. São Paulo: Hucitec, 1996.

Por uma outra globalização: do pensamento único à consciência universal.

Rio de Janeiro: Record, 2000.

. Altos e baixos na política. + BRASIL 501 D.C. MAIS!: Nacional, 2000.

\& SILVEIRA, Maria Laura. O Brasil: território e sociedade no início do século XXI. 9. ed. Rio de Janeiro: Record, 2001.

GONZALES, Elbio N. e BASTOS, Maria Inês. O trabalho volante na agricultura brasileira. In: SINGER, Paul [et all]. Capital e trabalho no campo. São Paulo: Hucitec, 1979. 
SINGER, Paul. Globalização e desemprego: Diagnóstico e alternativas. São Paulo: Contexto, 1998.

SILVA, José Graziano da. Progresso Técnico e Relações de Trabalho na Agricultura. São Paulo: Hucitec, 1981.

SILVA, J. G. (coord.). Estrutura Agrária e Produção de Subsistência na Agricultura Brasileira. São Paulo: Hucitec, 1978.

A Nova Dinâmica da Agricultura Brasileira. Campinas, São Paulo: UNICAMP/ IE, 1996.

. Tecnologia e agricultura familiar. Porto Alegre: Ed. Universidade, UFRGS, 1999a. O Novo Rural Brasileiro. Campinas, SP: UNICAMP.IE, 1999 b.

SOJA, Edward. Geografias Pós-Modernas. Rio de Janeiro: Jorge Zahar Editores, 1993.

Recebido para publicação em março de 2011. Aprovado para publicação em julho de 2011. 